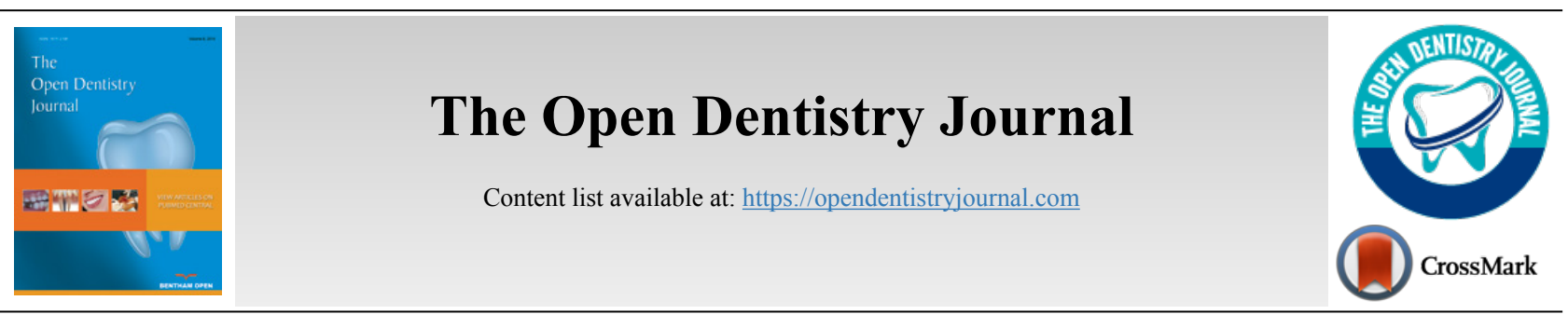

RESEARCH ARTICLE

\title{
Photobiomodulation vs. Placebo on Post-Bleaching Sensitivity and Color Change: A Split-Mouth Clinical Study
}

Caroline C. de Silva ${ }^{1}$, Cristiane de M. Alencar ${ }^{2}$, Brennda L. F. de Paula ${ }^{1}$, Fernanda F. de A. Jassé ${ }^{1}$, Jesuína L. N. Araújo ${ }^{1}$ and Cecy M. Silva ${ }^{1, *}$

\section{${ }^{1}$ Department of Dental Materials, School of Dentistry, Federal University of Pará, Belém, Brazil}

\begin{abstract}
:
Objective:

This study aimed to investigate the efficiency of Photobiomodulation (PBM) with low-level LASER therapy compared to placebo in postbleaching sensitivity and color change during a three-week office bleaching treatment.

Methods:

A split-mouth model was used to evaluate 21 subjects. The right and left hemi-archs were randomized to one of two groups: GP (placebo): simulated LASER application followed by tooth bleaching with 35\% hydrogen peroxide; and GL: treated with PBM followed by tooth bleaching with $35 \%$ hydrogen peroxide. A four-degree modified Visual Analog Scale (VAS) was used to assess tooth sensitivity after the application of an evaporative stimulus (stimulated pain). In addition, a daily questionnaire was used to measure unstimulated pain. The color change was measured using a spectrophotometer. The Friedman and Wilcoxon tests were used to analyze data sensitivity. Color results were statistically analyzed using Analysis Of Variance (ANOVA) followed by the Tukey post-hoc test.
\end{abstract}

Results:

There was no significant difference between GP and GL for stimulated pain evaluation ( $\mathrm{p}>0.05$ ). However, there was a significant difference between the groups for unstimulated pain evaluation $(\mathrm{p} \leq 0.05)$. In addition, $\Delta \mathrm{E}$ data did not reveal any significant difference in tooth color between groups at any time $(\mathrm{p}>0.05)$.

Conclusion:

PBM prevented post-bleaching sensitivity compared to placebo, based on the daily pain assessment questionnaires. PBM did not compromise the quality of bleaching treatments.

Keywords: Tooth bleaching, Dentin sensitivity, Photobiomodulation, Low-level laser therapy, Color, Hydrogen peroxide.

\begin{tabular}{|l|l|l|l|}
\hline Article History & Received: March 23, 2020 & Revised: April 22, 2020 & Accepted: April 29, 2020 \\
\hline
\end{tabular}

\section{INTRODUCTION}

Post-bleaching sensitivity has been widely reported in the literature; however, it is more frequently observed as a result of in-office tooth bleaching [1 - 3]. Post-bleaching sensitivity was previously explained due to the penetration of hydrogen peroxide (HP) molecules through dental tissue, which can lead to pulp inflammatory reactions $[4,5]$ The low molecular weight of HP and its byproducts allows its diffusion through

\footnotetext{
* Address correspondence to this author at the Department of Dental Materials, School of Dentistry, Federal University of Pará, Belém, Brazil; 66075-110;

E-mail: cecymsilva@gmail.com
}

mineralized tissues to reach the pulp chamber $[6,7]$

Recent studies have reported several ways to treat sensitivity, aiming to minimize the effects of post-bleaching sensitivity $[1,8-10]$. However, no desensitizing agent or forms of treatment have been totally effective or had a longlasting effect $[3,11,12]$. Low-level laser therapy has been extensively investigated in the literature since 1985 [13]. More recently, low-level laser therapy has been called Photobiomodulation (PBM) due to its biostimulative mechanism of action. However, some doubts remain regarding its use, such as the correct protocol, the use of low or high dosages, and even its association with a desensitizing agent. In addition, almost all clinical trials have evaluated the effect of 
PBM on dentin sensitivity and not on post-bleaching sensitivity [14]

The use of lasers has been widely described in recent literature for many dental disciplines, such as oral pathology $[15,16]$, conservative dentistry $[17,18]$, oral surgery [19], periodontology [20], and orthodontics [21] Low-power lasers have been tested for the treatment of DS using different irradiation protocols. Sgolastra et al.,(2011) [22] and He et al.,(2011) [23] performed systematic reviews on the efficacy of lasers for the treatment of DS. These authors were unable to determine whether the effectiveness of laser treatment was superior to a placebo, but they found that laser application was safe and did not have adverse effects. A recent meta-analysis conducted by Machado et al.,(2018) [24] concluded that more consistent studies should be conducted to draw definitive conclusions about the effect of PBM on DS. To date, no systematic review has investigated the efficiency of PBM in post-bleaching sensitivity. In addition, to the best of the authors' knowledge, only three randomized clinical trials have investigated the effect of PBM compared with placebos on reducing pain after in-office bleaching [25 - 27].

In vitro studies have shown important features of PBM's mechanism of action. The results revealed that their interaction with dental pulp causes a photo-biomodulating effect [28], leading to an increase in the metabolic activity of odontoblastic cells and, as a result, the obliteration of dentinal tubules by means of intensification of the production of tertiary dentin [29]. These possible consequences could interfere with the effectiveness of the bleaching treatment, and no clinical research has been done on this issue. Therefore, this study aimed to evaluate the effect of PBM on post-bleaching sensitivity in relation to placebo as well as the color changes resulting from in-office bleaching.

\section{MATERIALS AND METHODS}

This study was a randomized, double-blind, placebocontrolled clinical trial with a split-mouth design. The clinical investigation was approved (protocol 2,110,037) by the ethics committee of the local university. The study protocol was registered at https://clinicaltrials.gov under number NCT03514290 and followed the CONSORT statements [30]. All participants signed an informed consent form in full compliance with the Declaration of Helsinki [31].

Table 1. Inclusion and exclusion criteria.

\begin{tabular}{|l|l|}
\hline \multicolumn{2}{|c|}{ Eligibility Criteria } \\
\hline Inclusion Criteria & Exclusion Criteria \\
\hline $\begin{array}{l}\text { were aged between 18 to 30 years } \\
\text { old }\end{array}$ & had dentin hypersensitivity \\
\hline had good general and oral health & had congenital enamel defects \\
\hline had caries-free anterior teeth & had visible cracks on enamel \\
\hline had anterior-free restorations & had periodontal disease \\
\hline $\begin{array}{l}\text { had canines with shade A2 or } \\
\text { darker }\end{array}$ & had a previous bleaching procedure \\
\hline
\end{tabular}

\subsection{Eligibility Criteria}

The exclusion and exclusion criteria are detailed in Table 1. The subjects chewed pieces of orthodontic rubber to stimulate saliva production. The salivary flow rate was calculated, and the salivary $\mathrm{pH}$ was measured using a 510 Benchtop pH meter (Oakton Instruments ${ }^{\circledR}$; Vernon Hills, Illinois, USA). Patients who presented salivary flow with values between 1 and $2 \mathrm{mLmin}$ and $\mathrm{pH}$ between 6.5 and 7.0 were included in the study [8]

\subsection{Sample Size}

BioEstat program $^{\circledR}$ (Civil Society of Mamirauá, Tefé, AM, Brazil) was used. A pilot study was conducted with 12 subjects following the same protocol used in this clinical study. Statistical power of $80 \%$ and an $\alpha$ error of $5 \%$ were established for calculation. One point on a scale from 0 to 3 was used to consider a significant decrease in sensitivity. The sample loss rate was $20 \%$ at the end of the study. The sample size was 25 patients in total.

\subsection{Randomization and Blinding}

All subjects received both treatments. In view of this, only the hemi-arch was randomized. A number was assigned to each group: 1 for GP and 2 for GL. A numerical draw was carried out for each volunteer. The first number corresponded to the right hemi-arch and the remaining numbers corresponded to the left hemi-arch [32]. A "block" randomization was performed to avoid unbalanced groups with respect to the two sizes (right or left) at the end of the experiment.

Only one operator (CCS) performed all clinical appointments. A single-blind evaluator (C.M.A.) performed the dental sensitivity assessment of all volunteers. The subjects evaluated in this study did not know which hemi-arch had received PBM. A simulation of the LASER application was performed in the GP, that is, the tip of the equipment was positioned in the same way as in the GL group. However, in the GP, there was no light emission. The noise emitted by the LASER equipment during light emission was simulated using the iTalk Recorder application (Griffin Technology, Nashville, Tennessee, USA) for the iPhone 6 smartphone (Apple ${ }^{\circledR}$, Cupertino, CA, USA) [27, 32].

\subsection{Study Intervention}

Prior to PBM, dental prophylaxis was performed using a pumice stone (extra-fine pumice stone, Maquira ${ }^{\circledR}$; Maringá, PR, Brazil). The right and left maxillary/mandibular quadrants were randomized and allocated to one of two groups: GL: premolars, canines, and incisors of the corresponding hemiarch received laser irradiation prior to the bleaching treatment; and GP: for premolars, canines, and incisors of the corresponding hemi-arch, the laser tip was positioned similarly to GL but without light irradiation. The GL received PBM by LASER (Photon Laser III, DMC, São Carlos, SP, Brazil), at $808 \mathrm{~nm}$ at two perpendicular points using the infrared spectrum, both apical and central on the buccal surface of incisors, canines, and premolars. Emissions to the continuous mode were used; energy of $1.7 \mathrm{~J}$ at a dose of $60 \mathrm{~J} / \mathrm{cm}^{2}$ was applied to each point for $16 \mathrm{~s}$, with a spot size of $0.028 \mathrm{~cm}^{2}$ 
[32]. This protocol was carried out in accordance with the manufacturer's recommendations.

After PBM, all patients received the same bleaching treatment. The clinician isolated the gingival tissue surrounding the teeth to be bleached using a light-cured resin dam (Top Dam, FGM ${ }^{\circledR}$, Joinville, SC, Brazil). Then, tooth bleaching was performed. Four sessions with an interval of seven days were performed, and in each session, three 15-minute applications of $35 \%$ hydrogen peroxide gel were performed (Whiteness HP, $\mathrm{FGM}^{\circledR}$, Joinville, SC, Brazil). Peroxide gel was applied to the buccal surface of the incisors, canines, and premolars of the upper and lower hemi-arches. All patients received brushing kits containing a toothbrush (Indicator plus, Oral $\mathrm{B}^{\circledR}$; São Paulo, SP, Brazil) and vegan toothpaste without a desensitizing agent (Natural, Contente ${ }^{\circledR}$, Uberlândia, MG, Brazil). They were then instructed to use these items three times a day. In addition, volunteers were instructed to avoid acidic foods and drinks (citrus fruits, citrus juices, soft drinks, isotonics, wines, beers, coffees, and teas) throughout the clinical trial.

\subsection{Post-Bleaching Sensitivityevaluation}

To measure sensitivity after bleaching, a modified Visual Analog Scale (VAS) with an interval of 0 to 3 was used. The scale categories were as follows: absent (0), mild (1), moderate (2), and severe (3). Each score was related to facial expression in illustrative drawings to facilitate patients' perception of pain. Two forms of evaluation were used: stimulated (evaporative stimulus) and non-stimulated pain (questionnaire). The evaporative stimulus was produced using air from a triple syringe (DabiAtlante, Dental Products, Ribeirão Preto, SP, Brazil) that was positioned $1 \mathrm{~cm}$ from the tooth and exerted 40 psi of pressure for 5 seconds. Pain sensitivity assessments by means of stimulated pain were performed prior to the bleaching treatment and immediately after each bleaching session. A daily questionnaire was administered during the 21 days of treatment to assess the level of sensitivity caused by the treatment according to the patient's personal perception. The questionnaire was divided into teeth on the right side and teeth on the left side [27].

\subsection{Color Evaluation}

The color evaluation was performed using an Easyshade Advance 4.0 spectrophotometer (Zahnfabrik, Bad Säckingen, Germany) employing the CIE L*a*b* system. Color change values $(\Delta \mathrm{E})$ were obtained using the formula: $\Delta \mathrm{E}=\left\{(\Delta \mathrm{L})^{2}+\right.$ $\left.(\Delta \mathrm{a})^{2}+(\Delta \mathrm{b})^{2}\right\}^{1 / 2}$, where $\Delta \mathrm{L}^{*}=\mathrm{L}^{*}-\mathrm{L}^{*}, \Delta \mathrm{a}^{*}=\mathrm{a}^{*}$-a*, and e $\Delta \mathrm{b}^{*}$ $=b^{*}-b^{*}$ [7]. The evaluation was performed four times: before bleaching treatment (baseline) and after the first, second, and third bleaching sessions. The spectrophotometer equipment was positioned in the central region of each tooth.

\subsection{Statistical Analysis}

The reported sensitivity levels were analyzed statistically using the BioEstat program ${ }^{\circledR}$ (Civil Society Mamirauity levels were analyz). The Friedman $v s$. Wilcoxon statistical tests were used. The color change data was employed (using the BioEstat programer the first, and secondly, the patient's personal perception), followed by the Questi test. The level of significance was set at $5 \%$.

\section{RESULTS}

\subsection{Characteristics of the Included Participants}

A total of 38 participants were initially evaluated (Fig. 1). The baseline tooth color of the subjects was similar (GP- 4.2 [2.2]; GL- 4.4 [2.6]), and the mean and standard deviation of the subjects' age was 22.1 (5.8) years, ranging from 18 to 30 years. Twelve female participants $(57.14 \%)$ and 9 male participants $(42.86 \%)$ were included in the study.

\subsection{Evaporative Stimulus Combined with VAS}

The results for the different evaluation times are shown in Table 2. There were no significant differences between GP and GL at the different evaluation times ( $>00.05)$. Regarding intragroup analysis, there were also no significant differences between the times of sensitivity assessments in any group $(\mathrm{p}>0.05)$.

\subsection{Daily Pain Analysis (Questionnaire): 21-Day Follow-up}

The results at the different evaluation times are shown in Table 3. For the intergroup analysis, there was a significant difference $(p \leq 0.05)$ between GP and GL on the days of the bleaching sessions $\left(1^{\text {st }}\right.$ days, $8^{\text {th }}$, and $15^{\text {th }}$ day). The lowest sensitivity indices were observed for GL. In the intra-group analysis, both GP and GL presented significant differences $(\mathrm{p} \leq 0.05)$ on the days of the bleaching sessions $\left(1^{\text {st }}\right.$ days, $8^{\text {th }}$, and $15^{\text {th }}$ day) when compared to the other evaluated days.

Table 2. Median (interquartile deviation) of sensitivity recorded through evaporative stimulus in different evaluation times.

\begin{tabular}{|c|c|c|c|c|}
\hline Groups & \multicolumn{4}{|c|}{ Md $( \pm \mathbf{I Q R})$} \\
\hline- & Baseline & 1st session & 2nd session & 3rd session \\
\hline GP & $0(0) \mathrm{Aa}$ & $0(0) \mathrm{Aa}$ & $0(0) \mathrm{Aa}$ & $0(0) \mathrm{Aa}$ \\
\hline GL & $0(0) \mathrm{Aa}$ & $0(0) \mathrm{Aa}$ & $0(0) \mathrm{Aa}$ & \\
\hline
\end{tabular}

* Different uppercase letters represent intra-group statistical difference for the different tests applied at the same time, $\mathrm{p} \leq 0.05$. $* *$ Different lowercase letters represent inter-group statistical difference for the different tests applied at the same time, $\mathrm{p} \leq 0.05$. 


\section{Enrolment}

Volunteers assessed for eligibility $(\mathrm{n}=38)$
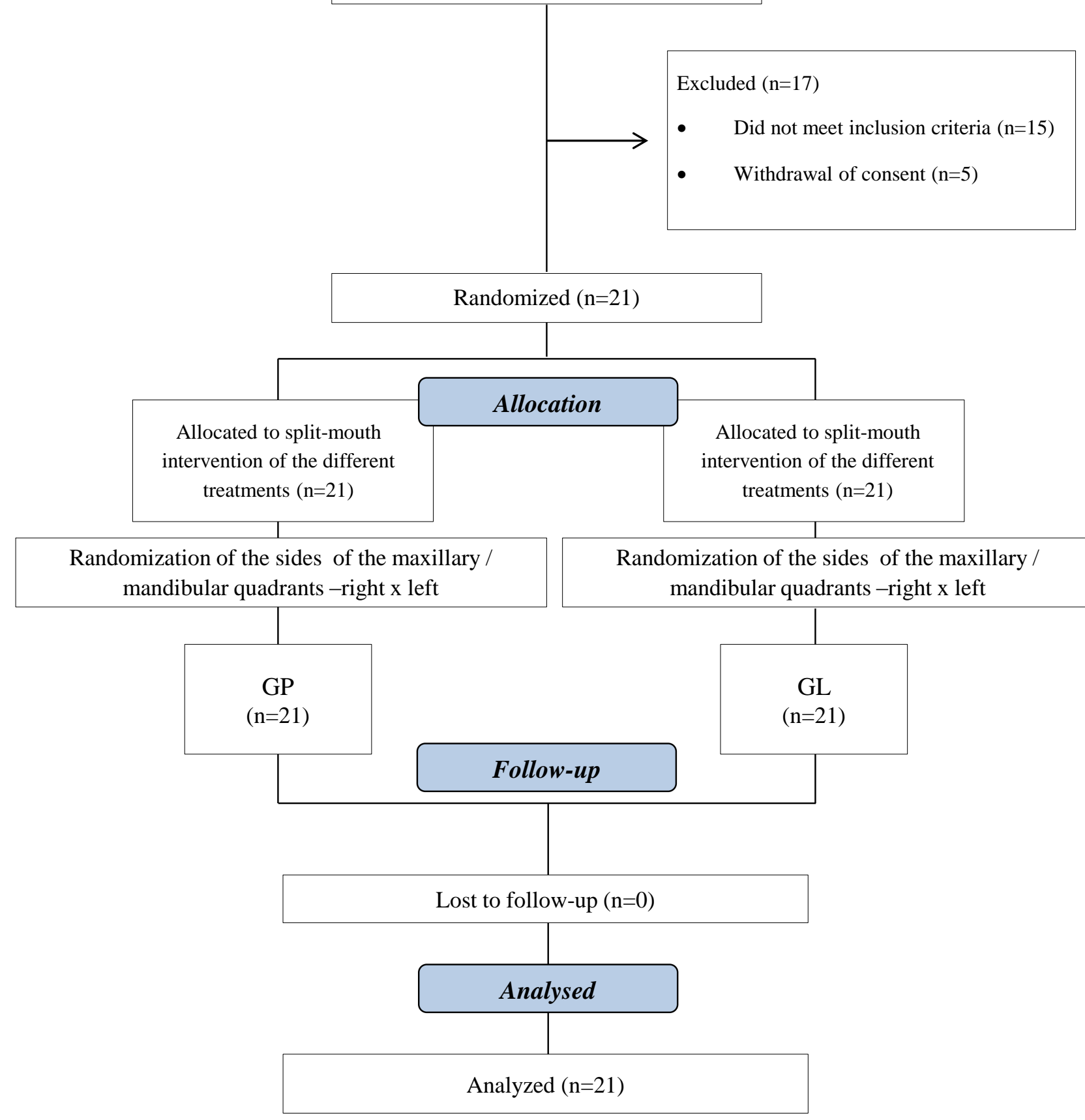

Fig. (1). Clinical trial study design followed the CONSORT statement. Details of recruitment, allocation and monitoring sequences.

Table 3. Median (interquartile deviation) of sensitivity recorded in the 21-day follow-up questionnaire.

\begin{tabular}{|l|l|l|l|l|l|l|l|}
\hline \multicolumn{9}{|c|}{ Md $( \pm \mathbf{Q Q R})$} \\
\hline 1st week & 1st day & 2nd day & 3rd day & 4th day & 5th day & 6th day & 7th day \\
\hline GP & $2(1) \mathrm{Ab}$ & $0(0) \mathrm{Ba}$ & $0(0) \mathrm{Ba}$ & $0(0) \mathrm{Ba}$ & $0(0) \mathrm{Ba}$ & $0(0) \mathrm{Ba}$ & $0(0) \mathrm{Ba}$ \\
\hline GL & $0.0(1) \mathrm{Aa}$ & $0(0) \mathrm{Ba}$ & $0(0) \mathrm{Ba}$ & $0(0) \mathrm{Ba}$ & $0(0) \mathrm{Ba}$ & $0(0) \mathrm{Ba}$ & $0(0) \mathrm{Ba}$ \\
\hline 2nd week & 8 th day & 9 th day & 10 th day & 11 th day & 12 th day & 13 th day & 14 th day \\
\hline GP & $2(1) \mathrm{Ab}$ & $0(0) \mathrm{Ba}$ & $0(0) \mathrm{Ba}$ & $0(0) \mathrm{Ba}$ & $0(0) \mathrm{Ba}$ & $0(0) \mathrm{Ba}$ & $0(0) \mathrm{Ba}$ \\
\hline GL & $1(1) \mathrm{Aa}$ & $0(0) \mathrm{Ba}$ & $0(0) \mathrm{Ba}$ & $0(0) \mathrm{Ba}$ & $0(0) \mathrm{Ba}$ & $0(0) \mathrm{Ba}$ & $0(0) \mathrm{Ba}$ \\
\hline
\end{tabular}


(Table ロ) cont......

\begin{tabular}{|c|c|c|c|c|c|c|c|}
\hline \multicolumn{8}{|c|}{ Md ( $( \pm$ IQR $)$} \\
\hline 1st week & 1st day & 2nd day & 3rd day & 4th day & 5th day & 6th day & 7th day \\
\hline 3rd Week & 15 th day & 16th day & 17th day & 18th day & 19th day & 20th day & 21th day \\
\hline GP & $3(1) \mathrm{Ab}$ & $0(0) \mathrm{Ba}$ & $0(0) \mathrm{Ba}$ & $0(0) \mathrm{Ba}$ & $0(0) \mathrm{Ba}$ & $0(0) \mathrm{Ba}$ & $0(0) \mathrm{Ba}$ \\
\hline GL & 1(1)Aa & $0(0) \mathrm{Ba}$ & $0(0) \mathrm{Ba}$ & $0(0) \mathrm{Ba}$ & $0(0) \mathrm{Ba}$ & $0(0) \mathrm{Ba}$ & $0(0) \mathrm{Ba}$ \\
\hline
\end{tabular}

* Different uppercase letters represent intra-group statistical difference for the different tests applied at the same time, $\mathrm{p} \leq 0.05$. ${ }^{* *}$ Different lowercase letters represent inter-group statistical difference for the different tests applied at the same time, $\mathrm{p} \leq 0.05$. ${ }^{* * *}$ VAS Modified, pain scores: $0=$ absent; 1 : light; 2 : moderate; 3 : severe.

Table 4. Means (M) and standard deviations (SD) of $\Delta E$ values, according to the experimental group and follow-up.

\begin{tabular}{|l|l|l|l|}
\hline & \multicolumn{3}{|c|}{ M ( \pm SD) } \\
\hline Groups & 1st session & 2nd session & 3 rd session \\
\hline GP & $4.53 \pm(2.4) \mathrm{Aa}$ & $5.44 \pm(4.7) \mathrm{Aa}$ & $5.81 \pm(5.5) \mathrm{Ab}$ \\
\hline GL & $4.80 \pm(3.4) \mathrm{Aa}$ & $5.85 \pm(3.4) \mathrm{Aa}$ & $5.90 \pm(4.4) \mathrm{Ab}$ \\
\hline
\end{tabular}

* Different uppercase letters represent intra-group statistical difference for the different tests applied at the same time, $\mathrm{p} \leq 0.05 . * *$ Different lowercase letters represent intergroup statistical difference for the different tests applied at the same time, $\mathrm{p} \leq 0.05$.

\subsection{Color Evaluation}

There was no significant difference between the groups ( $\mathrm{p}>$ $0.05)$. The intra-group comparison revealed commonality in the two study groups $(\mathrm{P}<0.05)$ (Table 4$)$.

\section{DISCUSSION}

Previous studies have reported a high incidence rate of tooth sensitivity after in-office bleaching procedures in which high concentrations of hydrogen peroxide were used [33 - 35]. Although generally classified as mild or moderate, the literature shows that sensitivity is a very common symptom following bleaching treatments [2, 7 - 9]. Hydrogen peroxide has a low molecular weight, which facilitates its penetration into dental tissue and, consequently resulting in tooth whitening. On the other hand, the low molecular weight of hydrogen peroxide promotes the release of inflammatory mediators in the pulp [36, 37].

Many in vitro studies have evaluated the effect of peroxides on dental pulp[38 - 42]. These studies have shown that the application time, the concentration of the bleaching agent, and the type of tooth may be related to pulp inflammation during bleaching. Simultaneously, clinical trials have evaluated the use of anti-inflammatory drugs in the prevention of post-bleaching sensitivity but have not yielded promising results $[43,44]$. The use of PBM in the prevention or treatment of post-bleaching sensitivity has been poorly investigated. For this reason, there has been no systematic review of this topic to date. This therapy has analgesic, antiinflammatory, and biomodulatory effects $[45,46]$. The photon energy is converted into chemical energy within the cell, forming ATP, which may lead to increased intracellular $\mathrm{Ca}^{+2}$ $[47,48]$. This will ultimately stimulate the modulation of fibroblast growth factor production, which in turn will stimulate cell proliferation $[49,50]$.This mechanism of action justifies the lower sensitivity reported in GL.

To date, only three clinical trials have evaluated the effect of PBM on post-bleaching sensitivity. The results of the present clinical study are consistent with those obtained by Moosavi et al., (2017) [25] and De Paula et al.,(2018) [27]. However, in the research carried out by Calheiros et al.,(2017) [26], PBM was not effective in the prevention and treatment of post-bleaching sensitivity. Variations in the composition of bleaching gels, especially $\mathrm{pH}$ and additives, and the decrease in the $\mathrm{pH}$ stability of some products may explain their results [25, 26]. In addition, there is no standardization of the protocol for the use of PBM in dentistry. Furthermore, the small number of clinical trials on this topic makes it difficult to reach a definitive conclusion and makes it impossible to perform a systematic review or meta-analysis on the clinical efficacy of this treatment on tooth sensitivity.

There is no treatment or clinical protocol considered the "gold standard" for the treatment of post-bleaching sensitivity. This makes it difficult for the clinician to make a decision. A recent clinical trial developed by Calheiros et al., (2017) [26] evaluated different protocols for the application of PBM in tooth bleaching. The author evaluated laser treatment before bleaching, after bleaching, and before and after bleaching, and concluded that there was no difference in sensitivity prevention among the three tested treatments. In the present clinical study, PBM was applied immediately before GL bleaching, aiming for a preventive effect.

There was significantly lower sensitivity in GL compared to GP. However, this difference was only detected in the nonstimulated pain (questionnaire), and no significant pain was verified with regard to the stimulated pain. According to Markowitz [7] the nature of sensitivity related to tooth bleaching is different from DS, as explained by Brannstrom [51]. For this reason, the inflammatory characteristics of the bleached tooth could be related to spontaneous pain. Further studies should be conducted to investigate this issue. Although GL presented less sensitivity than GP, light sensitivity was reported in GL. This shows that post-bleaching sensitivity treatment remains a challenge, and further clinical research is encouraged to evaluate different treatments and protocols.

Regarding color change, there was no difference in the quality of the bleaching treatment between GP and GL. This may be because the formation of a tertiary dentin layer may have been compromised by the oxidizing action of peroxide on pulp cells, as demonstrated by some authors in in vitro studies $[27,52]$. For this reason, there was no interference of PBM on dentin staining or bleaching.

The modified visual analog scale used in this study was 
proposed by Thomas Schiff et al. (2009 [53] This VAS is used to assess dentinal sensitivity in many clinical studies $(8,10,25)$. It makes it easier for the patient to classify their pain levels: absent (0), mild (1), moderate (2), and severe [3]. Despite the complexity of post-bleaching sensitivity treatments and the difficulty of establishing adequate methodologies for clinical research, this study showed satisfactory results for PBM. The main limitation of the split-mouth model is the risk that one treatment will affect the other treatment response, an effect known as carry-across [54]. However, there is no consistent evidence that the use of lasers on dental structures can generate any systemic effects on the body. Thus, the carry-across effect likely did not affect the results of this study. In addition, clinical studies depend on patients' discipline and commitment. This question is difficult to address by the researcher.

\section{CONCLUSION}

PBM decreased post-bleaching sensitivity compared to placebo when evaluating daily pain using a questionnaire (nonstimulated pain). PBM did not compromise the quality of the bleaching treatment.

\section{ETHICS APPROVAL AND CONSENT TO PARTICIPATE}

The study was approved by the ethics committee of the Federal University of Para, Brazil (protocol 2,110,037). The study protocol was registered at https://clinicaltrials.gov under number NCT03514290.

\section{HUMAN AND ANIMAL RIGHTS}

No animals were used in this research. All human research procedures followed were in accordance with the ethical standards of the committee responsible for human experimentation (institutional and national), and with the Helsinki Declaration of 1975, as revised in 2013.

\section{CONSENT FOR PUBLICATION}

All patients signed an informed consent form.

\section{AVAILIBILTY OF DATA \& MATERIALS}

The data supporting the findings of the article is available in the Plataforma Brasil - Human Research and Ethics Committee of the Institute of Health Sciences of the Federal University of Pará at http://plataformabrasil.saude.gov.br/login.jsf, reference number CAAE: 57534016.0.0000.0018.

\section{FUNDING}

None.

\section{CONFLICT OF INTEREST}

The authors declare no conflict of interest, financial or otherwise.

\section{ACKNOWLEDGEMENTS}

Declared none.

\section{REFERENCES}

[1] Parreiras SO, Szesz AL, Coppla FM, et al. Effect of an experimental desensitizing agent on reduction of bleaching-induced tooth sensitivity: A triple-blind randomized clinical trial. J Am Dent Assoc 2018; 149(4): 281-90.

[http://dx.doi.org/10.1016/j.adaj.2017.10.025] [PMID: 29439773]

[2] Rezende M, Loguercio AD, Kossatz S, Reis A. Predictive factors on the efficacy and risk/intensity of tooth sensitivity of dental bleaching: A multi regression and logistic analysis. J Dent 2016; 45: 1-6.

[http://dx.doi.org/10.1016/j.jdent.2015.11.003] [PMID: 26612623]

[3] Wang Y, Gao J, Jiang T, Liang S, Zhou Y, Matis BA. Evaluation of the efficacy of potassium nitrate and sodium fluoride as desensitizing agents during tooth bleaching treatment-A systematic review and meta-analysis. J Dent 2015; 43(8): 913-23.

[http://dx.doi.org/10.1016/j.jdent.2015.03.015] [PMID: 25913140]

[4] Benetti F, Gomes-Filho JE, Ferreira LL, et al. Hydrogen peroxide induces cell proliferation and apoptosis in pulp of rats after dental bleaching in vivo: Effects of the dental bleaching in pulp. Arch Oral Biol 2017; 81: 103-9.

[http://dx.doi.org/10.1016/j.archoralbio.2017.04.013]

[PMID: 28500951]

[5] Grazioli G, Valente LL, Isolan CP, Pinheiro HA, Duarte CG, Münchow EA. Bleaching and enamel surface interactions resulting from the use of highly-concentrated bleaching gels. Arch Oral Biol 2018; 87: 157-62.

[http://dx.doi.org/10.1016/j.archoralbio.2017.12.026]

[PMID: 29304422]

[6] Torres CR, Wiegand A, Sener B, Attin T. Influence of chemical activation of a $35 \%$ hydrogen peroxide bleaching gel on its penetration and efficacy--in vitro study. J Dent 2010; 38(10): 838-46.

[http://dx.doi.org/10.1016/j.jdent.2010.07.002] [PMID: 20633597]

[7] Markowitz K. Pretty painful: Why does tooth bleaching hurt? Med Hypotheses 2010; 74(5): 835-40.

[http://dx.doi.org/10.1016/j.mehy.2009.11.044] [PMID: 20045265]

[8] de Melo Alencar C, Castro da Silva R, Nogueira Araújo JL, Silva da Silveira AD, Martins Silva C. A clinical, randomized, double-blind study on the use of toothpastes immediately after at-home tooth bleaching. Am J Dent 2017; 30(5): 267-71.

[PMID: 29178730]

[9] Kara HB, Cakan U, Yilmaz B, Inan Kurugol P. Efficacy of diode laser and gluma on post-preparation sensitivity: A randomized split-mouth clinical study. J Esthet Restor Dent 2016; 28(6): 405-11. [http://dx.doi.org/10.1111/jerd.12230] [PMID: 27439664]

[10] Alexandrino LD, Alencar CM, Silveira ADSD, Alves EB, Silva CM Randomized clinical trial of the effect of NovaMin and CPP-ACPF in combination with dental bleaching. J Appl Oral Sci 2017; 25(3): 335-40.

[http://dx.doi.org/10.1590/1678-7757-2016-0408] [PMID: 28678953]

[11] Thiesen CH, Rodrigues Filho R, Prates LH, Sartori N. The influence of desensitizing dentifrices on pain induced by in-office bleaching. Braz Oral Res 2013; 27(6): 517-23.

[http://dx.doi.org/10.1590/S1806-83242013000600012] [PMID: 24346050]

[12] Pintado-Palomino K, Peitl Filho O, Zanotto ED, Tirapelli C. A clinical, randomized, controlled study on the use of desensitizing agents during tooth bleaching. J Dent 2015; 43(9): 1099-105.

[http://dx.doi.org/10.1016/j.jdent.2015.07.002] [PMID: 26159384]

[13] Liu HC, Lan WH. The combined effectiveness of the semiconductor laser with Duraphat in the treatment of dentin hypersensitivity. J Clin Laser Med Surg 1994; 12(6): 315-9.

[http://dx.doi.org/10.1089/clm.1994.12.315]

[14] Guanipa Ortiz MI, Alencar CM, Freitas De Paula BL, Alves EB, Nogueira Araújo JL, Silva CM. Effect of the casein phosphopeptideamorphous calcium phosphate fluoride (CPP-ACPF) and photobiomodulation (PBM) on dental hypersensitivity: A randomized controlled clinical trial. PLoS One 2019; 14(12)e0225501 [http://dx.doi.org/10.1371/journal.pone.0225501] [PMID: 31790452]

[15] Nammour S, Zeinoun T, Namour A, Vanheusden A, Vescovi P. Evaluation of different laser-supported surgical protocols for the treatment of oral leukoplakia: A long-term follow-up. Photomed Laser Surg 2017; 35(11): 629-38.

[http://dx.doi.org/10.1089/pho.2016.4256] [PMID: 28426376]

[16] Najeeb S, Khurshid Z, Zohaib S, Najeeb B, Qasim SB, Zafar MS. Management of recurrent aphthous ulcers using low-level lasers: A systematic review. Medicina (Kaunas) 2016; 52(5): 263-8. [http://dx.doi.org/10.1016/j.medici.2016.07.006] [PMID: 27717563] 
[17] Najeeb S, Khurshid Z, Zafar MS, Ajlal S. Applications of light amplification by stimulated emission of radiation (lasers) for restorative dentistry. Med Princ Pract 2016; 25(3): 201-11. [http://dx.doi.org/10.1159/000443144] [PMID: 26642047]

[18] Sung EC, Chenard T, Caputo AA, Amodeo M, Chung EM, Rizoiu IM. Composite resin bond strength to primary dentin prepared with Er, Cr:YSSG laser. J Clin Pediatr Dent 2005; 30(1): 45-9.

[http://dx.doi.org/10.17796/jcpd.30.1.el385u211tnu2574] [PMID: 16302599]

[19] Vitale MC, Sfondrini MF, Croci GA, et al. Diode laser-assisted surgical therapy for early treatment of oral mucocele in newborn patient: Case report and procedures checklist. Case Rep Dent 2018; 20183048429

[http://dx.doi.org/10.1155/2018/3048429] [PMID: 29854481]

[20] Dyer B, Sung EC. Minimally invasive periodontal treatment using the Er,Cr: YSGG laser. a 2-year retrospective preliminary clinical study. Open Dent J 2012; 6: 74-8.

[http://dx.doi.org/10.2174/1874210601206010074] [PMID: 22615717]

[21] Sfondrini MF, Calderoni G, Vitale MC, Gandini P, Scribante A. Is laser conditioning a valid alternative to conventional etching for aesthetic brackets? Eur J Paediatr Dent 2018; 19(1): 61-6. [PMID: 29569456]

[22] Sgolastra F, Petrucci A, Gatto R, Monaco A. Effectiveness of laser in dentinal hypersensitivity treatment: A systematic review. J Endod 2011; 37(3): 297-303.

[http://dx.doi.org/10.1016/j.joen.2010.11.034] [PMID: 21329811]

[23] He S, Wang Y, Li X, Hu D. Effectiveness of laser therapy and topical desensitising agents in treating dentine hypersensitivity: A systematic review. J Oral Rehabil 2011; 38(5): 348-58.

[http://dx.doi.org/10.1111/j.1365-2842.2010.02193.x] [PMID: 21223353]

[24] Machado AC, Viana ÍEL, Farias-Neto AM, et al. Is photobiomodulation (PBM) effective for the treatment of dentin hypersensitivity? A systematic review. Lasers Med Sci 2018; 33(4): 745-53.

[http://dx.doi.org/10.1007/s10103-017-2403-7] [PMID: 29204915]

[25] Moosavi H, Arjmand N, Ahrari F, Zakeri M, Maleknejad F. Effect of low-level laser therapy on tooth sensitivity induced by in-office bleaching. Lasers Med Sci 2016; 31(4): 713-9.

[http://dx.doi.org/10.1007/s10103-016-1913-z] [PMID: 26964798]

[26] Calheiros APC, Moreira MS, Gonçalves F, et al. Photobiomodulation in the prevention of tooth sensitivity caused by in-office dental bleaching. A randomized placebo preliminary study. Photomed Laser Surg 2017; 35(8): 415-20

[http://dx.doi.org/10.1089/pho.2017.4282] [PMID: 28783465]

[27] de Paula B, Alencar C, Ortiz M, Couto R, Araújo J, Silva C. Effect of photobiomodulation with low-level laser therapy combined with potassium nitrate on controlling post-bleaching tooth sensitivity: clinical, randomized, controlled, double-blind, and split-mouth study. Clin Oral Investig 2019; 23(6): 2723-32.

[http://dx.doi.org/10.1007/s00784-018-2715-4] [PMID: 30361793]

[28] Ferreira AN, Silveira L, Genovese WJ, et al. Effect of GaAIAs laser on reactional dentinogenesis induction in human teeth. Photomed Laser Surg 2006; 24(3): 358-65.

[http://dx.doi.org/10.1089/pho.2006.24.358] [PMID: 16875445]

[29] Tate Y, Yoshiba K, Yoshiba N, Iwaku M, Okiji T, Ohshima H. Odontoblast responses to GaAlAs laser irradiation in rat molars: An experimental study using heat-shock protein-25 immunohistochemistry. Eur J Oral Sci 2006; 114(1): 50-7. [http://dx.doi.org/10.1111/j.1600-0722.2006.00261.x] [PMID: 16460341]

[30] Needleman I, Worthington H, Moher D, Schulz K, Altman DG. Improving the completeness and transparency of reports of randomized trials in oral health: The CONSORT statement. Am J Dent 2008; 21(1): 7-12.

\section{[PMID: 18435368]}

[31] World Medical Association. World Medical Association Declaration of Helsinki: Ethical principles for medical research involving human subjects. JAMA 2013; 310(20): 2191-4.

[http://dx.doi.org/10.1001/jama.2013.281053] [PMID: 24141714]

[32] Alencar CM, De Paula BLF, Araújo JLN, Alves EB, De Albuquerque Jassé FF, Silva CM. Effect of low-level laser therapy combined with 5000 parts per million fluoride dentifrice on postbleaching sensitivity: A clinical, randomized, and double-blind study. J Esthet Restor Dent 2018; 30(4): 352-9.

[http://dx.doi.org/10.1111/jerd.12386] [PMID: 30079637]

[33] Kossatz S, Martins G, Loguercio AD, Reis A. Tooth sensitivity and bleaching effectiveness associated with use of a calcium-containing inoffice bleaching gel. J Am Dent Assoc 2012; 143(12): e81-7.

[http://dx.doi.org/10.14219/jada.archive.2012.0075] [PMID: 23204096]

[34] Tang B, Millar BJ. Effect of chewing gum on tooth sensitivity following whitening. Br Dent J 2010; 208(12): 571-7.

[http://dx.doi.org/10.1038/sj.bdj.2010.500] [PMID: 20512109]

[35] Palé M, Mayoral JR, Llopis J, Vallès M, Basilio J, Roig M. Evaluation of the effectiveness of an in-office bleaching system and the effect of potassium nitrate as a desensitizing agent. Odontology 2014; 102(2): 203-10.

[http://dx.doi.org/10.1007/s10266-013-0132-3] [PMID: 23934088]

[36] Soares DG, Basso FG, Hebling J, de Souza Costa CA. Concentrations of and application protocols for hydrogen peroxide bleaching gels: Effects on pulp cell viability and whitening efficacy. J Dent 2014; 42(2): 185-98.

[http://dx.doi.org/10.1016/j.jdent.2013.10.021] [PMID: 24239924]

[37] Soares DG, Basso FG, Hebling J, de Souza Costa CA. Immediate and late analysis of dental pulp stem cells viability after indirect exposition to alternative in-office bleaching strategies. Clin Oral Investig 2015; 19(5): 1013-20

[http://dx.doi.org/10.1007/s00784-014-1321-3] [PMID: 25248948]

[38] Vaz MM, Lopes LG, Cardoso PC, et al. Inflammatory response of human dental pulp to at-home and in-office tooth bleaching. J Appl Oral Sci 2016; 24(5): 509-17.

[http://dx.doi.org/10.1590/1678-775720160137] [PMID: 27812622]

[39] Kwon SR, Swift EJ Jr. Critical appraisal. In-office tooth whitening: Pulpal effects and tooth sensitivity issues. J Esthet Restor Dent 2014; 26(5): 353-8.

[http://dx.doi.org/10.1111/jerd.12121] [PMID: 25493305]

[40] Camargo SE, Valera MC, Camargo CH, Gasparoto Mancini MN, Menezes MM. Penetration of $38 \%$ hydrogen peroxide into the pulp chamber in bovine and human teeth submitted to office bleach technique. J Endod 2007; 33(9): 1074-7.

[http://dx.doi.org/10.1016/j.joen.2007.04.014] [PMID: 17931936]

[41] Costa CA, Riehl H, Kina JF, Sacono NT, Hebling J. Human pulp responses to in-office tooth bleaching. Oral Surg Oral Med Oral Pathol Oral Radiol Endod 2010; 109(4): e59-64.

[http://dx.doi.org/10.1016/j.tripleo.2009.12.002] [PMID: 20303048]

[42] Cartagena AF, Parreiras SO, Loguercio AD, Reis A, Campanha NH. In-office bleaching effects on the pulp flow and tooth sensitivity - case series. Braz Oral Res 2015; 29: 1-6.

[http://dx.doi.org/10.1590/1807-3107BOR-2015.vol29.0026] [PMID: 25627891]

[43] Charakorn P, Cabanilla LL, Wagner WC, et al. The effect of preoperative ibuprofen on tooth sensitivity caused by in-office bleaching. Oper Dent 2009; 34(2): 131-5.

[http://dx.doi.org/10.2341/08-33] [PMID: 19363967]

[44] Paula E, Kossatz S, Fernandes D, Loguercio A, Reis A. The effect of perioperative ibuprofen use on tooth sensitivity caused by in-office bleaching. Oper Dent 2013; 38(6): 601-8.

[http://dx.doi.org/10.2341/12-107-C] [PMID: 23586657]

[45] Silveira PCL, Streck EL, Pinho RA. Evaluation of mitochondrial respiratory chain activity in wound healing by low-level laser therapy. J Photochem Photobiol B 2007; 86(3): 279-82.

[http://dx.doi.org/10.1016/j.jphotobiol.2006.10.002] [PMID: 17113781]

[46] Reddy GK. Photobiological basis and clinical role of low-intensity lasers in biology and medicine. J Clin Laser Med Surg 2004; 22(2): 141-50.

[http://dx.doi.org/10.1089/104454704774076208] [PMID: 15165389]

[47] Fávaro-Pípi E, Ribeiro DA, Ribeiro JU, et al. Low-level laser therapy induces differential expression of osteogenic genes during bone repair in rats. Photomed Laser Surg 2011; 29(5): 311-7.

[http://dx.doi.org/10.1089/pho.2010.2841] [PMID: 21306231]

[48] Pirnat S. Versatility of an $810 \mathrm{~nm}$ diode laser in dentistry: An overview. J Laser Health Acad 2007; 4: 1-8.

[49] Hawkins D, Abrahamse H. Effect of multiple exposures of low-level laser therapy on the cellular responses of wounded human skin fibroblasts. Photomed Laser Surg 2006; 24(6): 705-14. [http://dx.doi.org/10.1089/pho.2006.24.705] [PMID: 17199470]

[50] Pereira AN, Eduardo C de P, Matson E, Marques MM. Effect of lowpower laser irradiation on cell growth and procollagen synthesis of cultured fibroblasts. Lasers Surg Med 2002; 31(4): 263-7. [http://dx.doi.org/10.1002/lsm.10107] [PMID: 12355572]

[51] Brannstrom M. The hydrodynamic theory of dentinal pain: Sensation in preparations, caries, and the dentinal crack syndrome. J Endod 
1986; 12(10): 453-7.

[http://dx.doi.org/10.1016/S0099-2399(86)80198-4] [PMID: 3465849]

[52] Godoy BM, Arana-Chavez VE, Núñez SC, Ribeiro MS. Effects of low-power red laser on dentine-pulp interface after cavity preparation. An ultrastructural study. Arch Oral Biol 2007; 52(9): 899-903.

[http://dx.doi.org/10.1016/j.archoralbio.2007.02.003]

[PMID: 17485070]

[53] Schiff T, Delgado E, Zhang YP, Cummins D, DeVizio W, Mateo LR.
Clinical evaluation of the efficacy of an in-office desensitizing paste containing $8 \%$ arginine and calcium carbonate in providing instant and lasting relief of dentin hypersensitivity. Am J Dent 2009; 22 Spec No A: $8 \mathrm{~A}-15 \mathrm{~A}$.

[PMID: 19472556]

[54] Pihlstrom BL, Barnett ML. Design, operation, and interpretation of clinical trials. J Dent Res 2010; 89(8): 759-72.

[http://dx.doi.org/10.1177/0022034510374737] [PMID: 20581353]

\section{C) 2020 Caldeira de Silva et al.}

This is an open access article distributed under the terms of the Creative Commons Attribution 4.0 International Public License (CC-BY 4.0), a copy of which is available at: (https://creativecommons.org/licenses/by/4.0/legalcode). This license permits unrestricted use, distribution, and reproduction in any medium, provided the original author and source are credited. 